\title{
Stigmatised attitudes in independent pharmacies associated with discrimination towards individuals with opioid dependence
}

\author{
Jason Luty, ${ }^{1}$ Pramod Kumar, ${ }^{2}$ Konstantinos Stagias $^{1}$
}

The Psychiatrist (2010), 34, 511-514, doi: 10.1192/pb.bp.109.028951

${ }^{1}$ Taylor Centre, Southend-on-Sea; ${ }^{2}$ Aston Court Resource Centre, Basildon

Correspondence to Jason Luty (jason.luty@yahoo.co.uk)

\begin{abstract}
Aims and method Dispensing of methadone to individuals with opioid dependence is a discretionary service and many independent pharmacies remain unwilling to do this. We aimed to determine whether there was any correlation between negative stigmatised attitude towards these individuals and the likelihood of methadone dispensing. The 20-point Attitude to Mental Illness Questionnaire (AMIQ) was used to assess stigmatised attitudes in a cluster randomised sample of managers of community pharmacies in England.
\end{abstract}

Results The response rate was 66\%. The AMIQ stigma scores had a median difference of 1 and effect size of 0.42 in favour of those pharmacies which dispensed methadone (mean $=0.53 ; n=138$ ) compared with those who did not (mean $=0.93$; $n=69 ; P<0.001)$.

Clinical implications The results show a clear behavioural distinction (discrimination) based on stigmatised attitudes towards individuals with opioid dependence. This may arise because managers with stigmatised attitudes refuse to dispense methadone to this group. Conversely, familiarity with these individuals may have a de-stigmatising effect.

\section{Declaration of interest None.}

Stigma is a social construction that devalues people as a result of a distinguishing characteristic or mark. ${ }^{1}$ People with mental illness are highly stigmatised and this contributes to their suffering and delays or prevents recovery. $^{2}$ Hence many governments, including the UK, have policies intended to reduce the stigma and discrimination associated with mental illness. ${ }^{3}$ This is recognised in the UK Safer Services report where the stigma of mental illness was identified as a major barrier to suicide prevention and treatment of depression. ${ }^{4}$ Consequently, several anti-stigma campaigns have been launched in the UK, including the See Me campaign in Scotland and Time to Change campaign in England.,

Crisp et al's large survey for the Changing Minds campaign showed that people with alcoholism and drug addiction are the most stigmatised group of all of those with mental illness. ${ }^{5}$ The majority of respondents regarded people with substance use disorders as dangerous, unpredictable and hard to talk with, whereas three out of five respondents blamed the patients for their condition an opinion endorsed by only 1 in 16 in relation to schizophrenia.

Methadone is the drug most commonly used for treatment of heroin addiction in Britain. ${ }^{7}$ It not only reduces heroin use, but also improves health, reduces infectious disease transmission and death from overdose. ${ }^{8}$ The National Treatment Agency for Substance Misuse has estimated that 160000 people take prescribed methadone in England and Wales every year. The risks of illicit diversion of prescribed methadone have led the UK government to recommend that methadone treatment be initiated with daily dispensing with direct supervision of consumption by community pharmacists. ${ }^{10,11}$ Large national pharmacy chains (such as Boots and Allcures.com) have unified policies allowing dispensing of methadone to individuals with opioid dependence. By contrast, at independent pharmacies dispensing of methadone is left to the discretion of the managers (who are often pharmacists). This decision is likely to be made based on financial considerations (dispensing and supervision fees) and experience or fear of the client group (who are often suspected of shoplifting or causing disruption within the pharmacy shop). Finding pharmacies willing to dispense methadone is a particular problem in rural areas where individuals may have to travel considerable distances. This can be an important factor in treatment drop-outs.

The object of our study was to determine whether there was any correlation between negative stigmatised attitude towards individuals with opioid dependence and the likelihood of methadone dispensing. This was also a practical 
way of validating the Attitude to Mental Illness Questionnaire (AMIQ) and showing whether stigmatised attitudes as measured using the questionnaire had any behavioural consequences ('discrimination').

\section{Method}

We contacted managers of independent retail pharmacies, identified in regions selected at random from the 800 standard trunk dialling code areas listed in the British Telecom online directory. Areas were selected using the randomisation function of the Stats Direct statistical package (version 2.4; www.statsdirect.com). We asked the managers to complete the AMIQ. Attempts were made to contact all independent pharmacies in each of the 20 selected areas. The 5-item AMIQ is a brief, self-completion questionnaire. $^{12,13}$ A short fictitious vignette describing an imaginary patient was read to participants ('John has been injecting heroin daily for 1 year. He has started in treatment and wants to start on a prescription for methadone'). Participants subsequently answered five questions (the questionnaire can be viewed in an online supplement to this paper), scored on a 5-point Likert scale (maximum +2 , minimum -2) with blank questions; 'neutral' and 'don't know' scored zero. The maximum possible score ranged from -10 to +10 . The AMIQ has been shown to have good psychometric properties in a sample of over 800 members of the UK general public (one component accounted for $80.2 \%$ of the variance; test-retest reliability was 0.702 (Pearson's correlation coefficient); alternate test-reliability $v$. Corrigan's attribution questionnaire was 0.704 (Spearman's rank correlation rho); Cronbach's alpha was 0.93). ${ }^{13}$

Data analysis was performed using randomisation, correlation coefficients and non-parametric (Mann-Whitney) tests to generate and compare differences in subgroups using the Stats Direct statistical package on Windows. Shapiro-Wilk test showed significant non-normality for the data indicating the need for non-parametric tests in the analysis.

\section{Results}

Results were received for 207 participants (response rate $66 \%$ ). The mean AMIQ score for individuals with opioid dependence was 0.53 (s.e. $=0.24$; median 0 ; interquartile range (IQR) -1 to 3) for managers whose pharmacy dispensed methadone $(n=138)$ compared with the mean score of -0.93 (s.e. $=0.29$; median -1 ; IQR -2 to $1 ; n=69$ ) for the managers of the non-dispensing pharmacies. There was a statistically significant difference $(P<0.001$; MannWhitney $U$-test; median difference 1; effect size 0.42).

\section{Discussion}

The study shows that approximately a third of independent pharmacies chose not to dispense methadone to individuals with opioid dependence. The managers of these pharmacies, who are the principle policy makers, have a significantly more stigmatised view of this client group than managers of pharmacies that do provide this discretionary service. There are two possible explanations for this observation. First, pharmacy managers with a negative view of individuals with opioid dependence may wish to avoid having them attending their shop, presumably because of concerns about shoplifting or disruption. Of course, staff attitudes influence clients' behaviour, hence pharmacy staff with stigmatised attitudes towards opioid users may provoke aggressive or antisocial responses from those clients. Alternatively, familiarity with such individuals may reduce the perceived stigma among staff in pharmacies where methadone is dispensed and, presumably, individuals with opioid dependence are frequently in contact. In this case, exposure to treatment-seeking individuals with opioid dependence can be considered to have an anti-stigma effect with a modest effect size (0.42).

The managers-reported mean AMIQ scores of 0.53 and -0.93 for dispensing and non-dispensing pharmacies respectively are highly comparable with the mean score of +0.58 for members of the general population observed towards a recovering intravenous drug user. There is often a 'glass ceiling' at an AMIQ score of +1 above which it is very difficult for people with mental illness to exceed. ${ }^{14}$ By comparison, people with diabetes or Christians typically generate a mean score around +5 , whereas relapsed intravenous drug addicts and criminals typically score around $-5 .{ }^{13}$

The results are also important because they clearly demonstrate practical consequences (discrimination) based on negative stigmatised attitudes measured by the AMIQ.

\section{Clinical implications}

Daily supervised dispensing of methadone to individuals with opioid dependence has been recommended in Britain since the early 1990s, when more people died from methadone overdose (much of which was diverted from prescriptions onto the black market) than from heroin. ${ }^{10,11}$ Provision of methadone from accessible community pharmacies is essential given the effectiveness of this treatment. ${ }^{8}$ The majority of pharmacies in England provide this service - dispensing of methadone is available from those pharmacies who are part of national chains and also from the majority of independent pharmacies. Hence in many areas, particularly urban areas, there is readily accessible provision of methadone treatment to those addicted to opioids. Consequently, the main objective of the study was to provide validation of the AMIQ anti-stigma questionnaire by showing behavioural consequences.

In sociological terms, discrimination is the tendency to treat people who have identical relevant characteristics differently. Although the term discrimination has implications of misconduct, this is not automatically the case. For example, several pharmacies may be closely located and there would not be sufficient demand for two neighbouring pharmacies to provide methadone. Similarly, there is often some training and special facilities required for pharmacies to provide supervised consumption facilities. However, it also remains possible that the managers of some pharmacies are discriminating against individuals with opioid dependence because of prejudice or adverse experiences. Attempts to reduce prejudice and stigma are currently being 
introduced and these are likely to be just as applicable to pharmacy staff as other healthcare professionals.

\section{Methods to reduce the stigma of mental illness}

Methods to reduce stigma are extensively discussed in other reports. ${ }^{14}$ Promoting direct interpersonal contact with people who have mental illness may be an effective strategy, but the amount of contact required remains unknown. ${ }^{15-18}$ Indeed, this study may indicate that exposure to individuals with opioid dependence may reduce the perceived stigma. For example, the staff in pharmacies where methadone is prescribed presumably have frequent contact with opioiddependent illness. It is therefore possible that this familiarity reduces the stigmatised attitudes of these pharmacy staff. This contrasts with the interpretation that pharmacy staff who have a negative view of heroin addicts may be choosing not to dispense methadone. Although the difference was modest, it was highly statistically significant. This is highly comparable with other research in which a brief face-to-face intervention (motivational interviewing) was carried out with the aim to reduce the stigma of alcoholism perceived by members of the general public (effect size 0.43). ${ }^{19}$ By comparison, Wolff $e t ~ a l^{16}$ reported a labour-intensive controlled study of the effect of a public education campaign on community attitudes towards people with mental illness which involved contact with people with mental illness in the experimental sample. It produced effect sizes of 1.23 for fear and exclusion, 1.22 for social control and 0.66 for goodwill. Presenting people with substance use problems in a positive manner (by emphasising abstinence in treatment) produced an effect size of 1.5.

There are many other initiatives that have been tried to reduce the stigma of mental illness, especially the Time to Change campaign (www.time-to-change.org.uk). ${ }^{20}$ Unfortunately, there have been reports that national anti-stigma campaigns are not particularly effective. ${ }^{6,21-24}$

\section{Instruments for measuring stigma}

There remains no agreed gold standard interview against which to validate a stigma questionnaire. No stigma instrument has been validated against behavioural discrimination. For example, the Opinions About Mental Illness questionnaire is a self-completion instrument widely used to measure stigmatised attitudes towards mental illness. ${ }^{25}$ However, it measures attitudes towards the causes and treatment of mental illness rather than attitudes towards people with mental illness. Ritsher et $a l^{26}$ have validated a 29-item self-completion instrument (the Internalized Stigma of Mental Illness scale) that can be used to determine the degree of stigma experienced by people with mental illness. However, it was not designed to determine the attitude of members of the general population towards people with mental illness. The Community Attitudes Towards Mental Illness scale is useful when assessing attitudes towards various aspects of mental illness although, once again, this instrument is interviewer-rated. ${ }^{27}$ Crisp et $a l^{5}$ used a Likert scale in a large UK survey for the Changing Minds campaign. However, this used interview questionnaires that are too costly and cumbersome for routine use in other projects, especially where selfcompletion questionnaires are necessary.

Other instruments have been employed to measure stigmatised attitudes within the general population, although few have been fully validated. Pinfold et $a l^{18}$ used a questionnaire with Likert response in 472 secondary school children. Unfortunately, the questionnaire referred only to 'people with mental illness.' This is similar to Corrigan's attributions questionnaire. ${ }^{2}$ These instruments cannot be used to compare attitudes towards those with mental illness with attitudes towards other groups such as those without mental illness or those addicted to opioids (who by many people are not seen as having a mental illness).

The AMIQ was used in this report as it was the most appropriate available instrument for this postal survey. The AMIQ was developed as a short self-report questionnaire to assess stigmatised attitudes towards people with mental illness. It has good psychometric properties and was validated in a sample of over 1000 UK adults. ${ }^{12,13}$

\section{Strengths and limitations}

The response rate was reasonably good (over 66\%) and probably involves a representative sample of independent pharmacy managers at 20 different sites across England. The study presented a hypothetical person with opioid dependence. This is less accurate than real experience. The views expressed may be influenced by social desirability bias. Consequently, the project assessed actual behaviour (whether the pharmacy chose to dispense methadone to opioid addicts or not) rather than relying simply on surrogate measures.

The results from other similar studies show a negative view of people with active substance use disorder and suggest that participants had little reservation about indicating their disapproval of these disorders. ${ }^{13,14}$ This is confirmed in other reports. ${ }^{5}$ This would indicate that social disability bias had only a modest effect. Furthermore, social desirability bias would affect managers at both dispensing and non-dispensing pharmacies.

Overall, the report shows clearly that rating scales such as the AMIQ can usefully and meaningfully be applied in the context of substance dependence and the relationship between clients and treatment providers.

\section{About the authors}

Jason Luty is Consultant in Addictions Psychiatry, South Essex Partnership NHS Trust, and Honorary Consultant in Addictions Psychiatry, Cambridge and Peterborough Mental Health NHS Trust; Pramod Kumar is Staff Grade in General Psychiatry, Basildon; Konstantinos Stagias is ST6 in General Adult Psychiatry, South Essex Partnership NHS Trust.

\section{References}

1 Biernat M, Dovidio JF. Stigma and stereotypes. In The Social Psychology of Stigma (eds TF Heatherton, RE Kleck, MR Hebl): 88-125. Guilford Press, 2000.

2 Corrigan $P$, Markowitz FE, Watson A Rowan D Kubiak MA An attribution model of public discrimination towards people with mental illness. J Health Soc Behav 2003; 44: 162-79. 
3 Darzi A. Our NHS, Our Future. NHS Next Stage Review: Interim Report. Department of Health, 2007.

4 Appleby L. Safer Services. Department of Health, 1999.

5 Crisp AH, Gelder M, Goddard E, Meltzer H. Stigmatization of people with mental illness: a follow-up study within the Changing Minds campaign of the Royal College of Psychiatrists. World Psychiatry 2005; 4: $106-13$.

6 Mehta N, Kassam A Leese M, Butler G, Thornicroft G. Public attitudes towards people with mental illness in England and Scotland, 19942003. Br J Psychiatry 2009; 194: 278-84.

7 Joseph R, Moselhy HF. National survey of methadone prescribing for maintenance treatment: 'opiophobia' among substance misuse services? Psychiatr Bull 2005; 29: 459-61.

8 Ward J, Hall W, Mattick RP. Role of maintenance treatment in opioid dependence. Lancet 1999; 353: 221-6.

9 Best D, Campbell A. National Prescribing Audit: An Assessment of Prescribing Practices for Opioid Substitution Treatment in England, 20042005. National Treatment Agency for Substance Misuse, 2007.

10 Home Office. Reducing Drug Related Deaths. Home Office, 2000.

11 Department of Health (England), the Scottish Government, Welsh Assembly Government, Northern Ireland Executive. Drug Misuse and Dependence: UK Guidelines on Clinical Management. Department of Health, 2007.

12 Cunningham JA, Sobell LC, Chow VMC. What's in a label? The effects of substance types and labels on treatment considerations and stigma. J Stud Alcohol 1993; 54: 693-9.

13 Luty J, Fakuda FW, Umoh O, Gallagher J. Validation of a short instrument to measure stigmatised attitudes towards mental illness. Psychiatr Bull 2006; 30: 257-60.

14 Luty J, Rao H, Arokiadass SMR, Easow JM, Sarkhel A. The repentant sinner: methods to reduce stigmatised attitudes towards mental illness. Psychiatr Bull 2008; 32: 327-32.

15 Penn DL, Guynan K, Daily T, Spaulding WD, Garbin P, Sullivan M Dispelling the stigma of schizophrenia. Schizophr Bull 1994; 20: 567-77.
16 Wolff G, Pathare S, Craig T, Leff J. Public education for community care. A new approach. Br J Psychiatry 1996; 168: 441-7.

17 Corrigan PW, Penn DL. Lessons from social psychology on discrediting psychiatric stigma. Am Psychol 1999; 54: 765-76.

18 Pinfold V, Toulmin H, Thornicroft G, Huxley P, Farmer P, Graham T. Reducing psychiatric stigma and discrimination: evaluation of educational interventions in UK secondary schools. $\mathrm{Br} J$ Psychiatry 2003; 182: 342-6.

19 Luty J, Umoh O, Nuamah F. Effect of brief motivational interviewing on stigmatised attitudes towards mental illness. Psychiatr Bull 2009; 33: 212-4.

20 Mayville E, Penn DL. Changing societal attitudes towards persons with severe mental illness. Cogn Behav Practice 1998; 5: 241-53.

21 Paykel ES, Hart D, Priest RG. Changes in public attitudes to depression during the Defeat Depression Campaign. Br J Psychiatry 1998; 173: 51922.

22 Luty J, Umoh O, Sessay M, Sarkhel A. Effectiveness of Changing Minds campaign factsheets in reducing stigmatised attitudes towards mental illness. Psychiatr Bull 2007; 31: 377-81.

$23 \mathrm{Knox} T$, Smith J, Hereby $\mathrm{H}$. Risk of suicide and related adverse outcomes after exposure to a suicide prevention programme in the US air force: cohort study. BMJ 2003; 327: 1376-8.

24 Penn DL, Chamberlin C, Mueser KT. The effects of a documentary film about schizophrenia on psychiatric stigma. Schizophr Bull 2003; 29: 383-91.

25 Struening EL, Cohen J. Factor invariance and other psychometric characteristics of five opinions about mental illness factors. Educ Psychol Meas 1963; 23: 289-98.

26 Ritsher JB, Otilingam PG, Grajales M. Internalized stigma of mental illness: psychometric properties of a new measure. Psychiatry Res 2003; 121: $31-49$.

27 Taylor SM, Dear MJ, Hall GB. Attitudes towards the mentally ill and reactions to mental health facilities. Soc Sci Med 1979: 130: 281-90. 